\title{
The Association Between Preoperative Spinal Cord Rotation and Postoperative C5 Nerve Palsy
}

\author{
Mark S. Eskander, MD, Steve M. Balsis, PhD, Chris Balinger, MD, Caitlin M. Howard, MD, \\ Nicholas W. Lewing, MD, Jonathan P. Eskander, MD, Michelle E. Aubin, MD, Jeffrey Lange, MD, \\ Jason Eck, DO, MS, Patrick J. Connolly, MD, and Louis G. Jenis, MD \\ Investigation performed at the University of Massachusetts Medical Center, Worcester, Massachusetts
}

\begin{abstract}
Background: C5 nerve palsy is a known complication of cervical spine surgery. The development and etiology of this complication are not completely understood. The purpose of the present study was to determine whether rotation of the cervical spinal cord predicts the development of a C5 palsy.
\end{abstract}

Methods: We performed a retrospective review of prospectively collected spine registry data as well as magnetic resonance images. We reviewed the records for 176 patients with degenerative disorders of the cervical spine who underwent anterior cervical decompression or corpectomy within the $\mathrm{C} 4$ to $\mathrm{C} 6$ levels. Our measurements included area for the spinal cord, space available for the cord, and rotation of the cord with respect to the vertebral body.

Results: There was a $6.8 \%$ prevalence of postoperative $C 5$ nerve palsy as defined by deltoid motor strength of $\leq 3$ of 5 . The average rotation of the spinal cord (and standard deviation) was $2.8^{\circ} \pm 3.0^{\circ}$. A significant association was detected between the degree of rotation $\left(0^{\circ}\right.$ to $5^{\circ}$ versus $6^{\circ}$ to $10^{\circ}$ versus $\geq 11^{\circ}$ ) and palsy (point-biserial correlation $=0.94 ; p<0.001$ ). A diagnostic criterion of $6^{\circ}$ of rotation could identify patients who had a C5 palsy (sensitivity $=1.00$ [95\% confidence interval, 0.70 to 1.00 ], specificity $=0.97$ [ $95 \%$ confidence interval, 0.93 to 0.99 ], positive predictive value $=0.71$ [ $95 \%$ confidence interval, 0.44 to 0.89 ], negative predictive value $=1.00$ [95\% confidence interval, 0.97 to 1.00$]$ ]).

Conclusions: Our evidence suggests that spinal cord rotation is a strong and significant predictor of $\mathrm{C} 5$ palsy postoperatively. Patients can be classified into three types, with Type 1 representing mild rotation $\left(0^{\circ}\right.$ to $\left.5^{\circ}\right)$, Type 2 representing moderate rotation $\left(6^{\circ}\right.$ to $\left.10^{\circ}\right)$, and Type 3 representing severe rotation $\left(\geq 11^{\circ}\right)$. The rate of C5 palsy was zero of 159 in the Type-1 group, eight of thirteen in the Type- 2 group, and four of four in the Type-3 group. This information may be valuable for surgeons and patients considering anterior surgery in the C4 to $\mathrm{C} 6$ levels.

Level of Evidence: Prognostic Level II. See Instructions for Authors for a complete description of levels of evidence.

$\mathrm{T}$ reatment for stenosis of the cervical spine canal typically includes surgical decompression and/or stabilization ${ }^{1-5}$. Cervical spine surgery can be associated with complications, some of which are serious and not well understood. For example, C5 nerve palsy remains a complication of these surgical procedures and may result in muscle weakness, brachialgia, numbness, and patient dissatisfaction ${ }^{6-8}$. A large retrospective review demonstrated that the rate of $\mathrm{C} 5$ nerve palsy was $6.7 \%$ for all patients undergoing decompressive surgery at the C5 level'. Many studies have evaluated the etiology of the development of C5 nerve palsy and possible modifications to prevent this operative complication ${ }^{6,10,11}$. Causes of postoperative C5 palsy include posterior drift of the cord, reperfusion injury, brachial neuritis, thermal injury associated with the use of the high-speed burr, loading of the spine in the prone position, and overgrowth of the superior articular process ${ }^{6,12-15}$. Other investigators have noted that this complication is not isolated to $\mathrm{C} 5$, and in fact $\mathrm{C} 6$ to $\mathrm{C} 8$ palsies have been associated with impairment of the respective nerve roots after laminoplasty ${ }^{1,11,13-16}$. A recent report indicated that open-door

Disclosure: None of the authors received payments or services, either directly or indirectly (i.e., via his or her institution), from a third party in support of any aspect of this work. One or more of the authors, or his or her institution, has had a financial relationship, in the thirty-six months prior to submission of this work, with an entity in the biomedical arena that could be perceived to influence or have the potential to influence what is written in this work. No author has had any other relationships, or has engaged in any other activities, that could be perceived to influence or have the potential to influence what is written in this work. The complete Disclosures of Potential Conflicts of Interest submitted by authors are always provided with the online version of the article. 
The Journal of Bone \& Joint Surgery $\cdot$ Jbjs.org Volume 94-A · Number $17 \cdot$ September 5, 2012
The Association Between Preoperative Spinal Cord Rotation and Postoperative C5 Nerve Palsy laminoplasty was associated with an increased risk for the development of segmental motor paralysis as compared with doubledoor laminoplasty ${ }^{17}$. The theory was that the asymmetric opening and subsequent rotation of the spinal cord in the open-door group led to increased nerve root tension and the development of a palsy.

The purpose of the present study was to identify whether spinal cord rotation was a predictor of postoperative C5 nerve palsy.

\section{Materials and Methods}

This study is a retrospective review of prospectively collected spine registry 1 data as well as magnetic resonance imaging (MRI) data. Data were obtained from the University of Massachusetts Spine Center, which has an in-house registry that collects data including the Neck Disability Index $(\mathrm{NDI})^{18}$ and Short Form-36 (SF-36) ${ }^{19}$ scores for all patients who are managed at the center. We reviewed the records of 203 patients who presented to one of three academic spine surgeons in the years 2006 to 2009 and who had degenerative disorders of the cervical spine that were treated with primary anterior cervical decompressive surgery from C4 to C6. The registry data were reviewed for demographic characteristics, comorbidities, symptoms, functional outcome scores, and MRI measurements. Twenty-seven patients were excluded from the study because of missing information. C5 nerve palsy in this study was defined as a manual muscle testing score of $\leq 3$ on a scale of 5 by the attending spine surgeons, who were blinded to other variables in the study. We used three MRI measurements, which included the cross-sectional area for the spinal cord, the space available for the cord (as indicated by the anterior-to-posterior diameter at the widest portion of the canal), and rotation of the spinal cord relative to the vertebral body and canal (as indicated by the difference between the degree of rotation of the vertebral body and the degree of rotation of the spinal cord). For our analysis, we classified patients into three types, with Type 1 indicating mild rotation $\left(0^{\circ}\right.$ to $\left.5^{\circ}\right)$, Type 2 indicating moderate rotation $\left(6^{\circ}\right.$ to $\left.10^{\circ}\right)$, and Type 3 indicating severe rotation $\left(\geq 11^{\circ}\right)$. All measurements were obtained at the site of surgical decompression. These measurements were selected as a means of characterizing the amount of compression and displacement that affected the spinal cord within the canal. Postoperative $\mathrm{C} 5$ nerve palsies were correlated against all preoperative variables. Figures 1-A, 1-B, and 1-C depict the three measurements we used for this study. The observer performing the measurements was blinded to the outcomes and the preoperative variables. All measurements were made in triplicate, and the measurements were averaged. To control for intraobserver bias, Observer 1 then repeated measurements for twenty patients who were chosen at random. A second observer then recorded measurements for those same twenty patients to test for reproducibility.

All magnetic resonance images were made with use of a commercially available Siemens Magnetom Symphony 1.5-T MRI machine (Siemens Medical Solutions, Malvern, Pennsylvania). All measurements were made on T2weighted axial images with use of iSite Philips Global PACS (picture archiving and communications system) (version 3.5.86.0; Philips Healthcare, Andover,

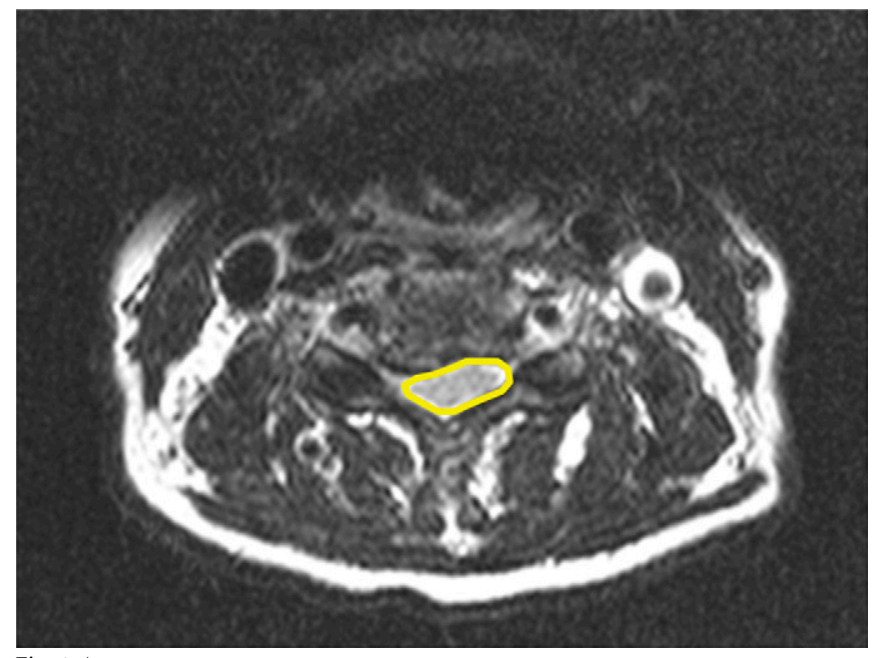

Fig. 1-A

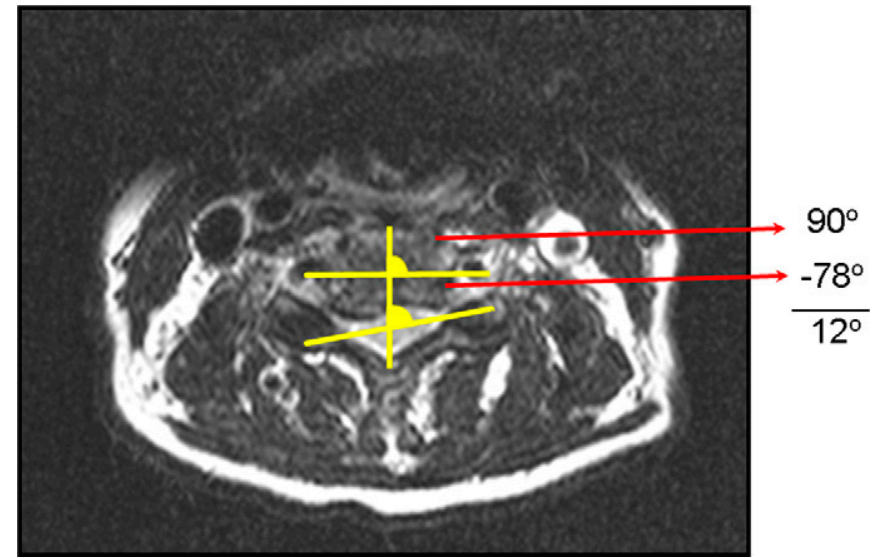

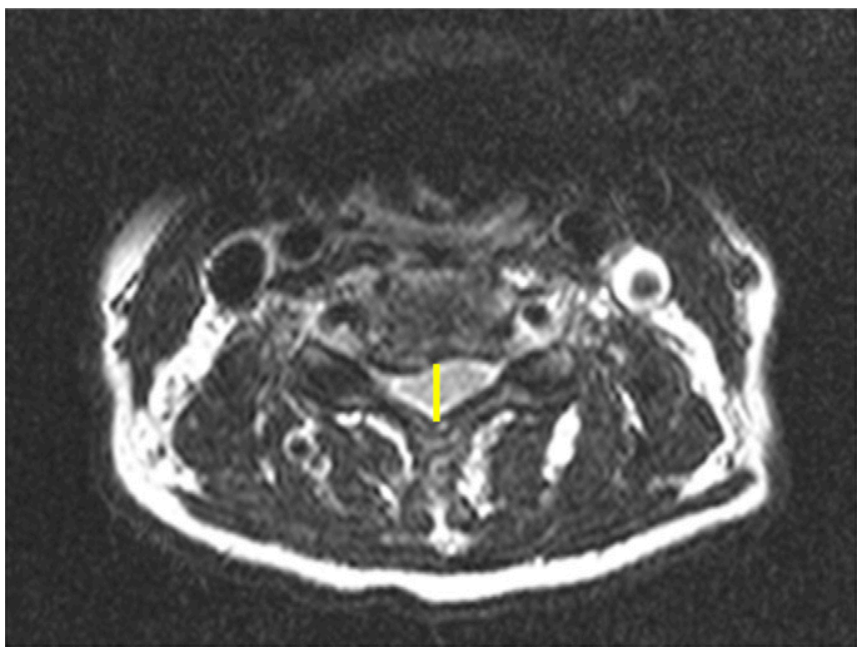

Fig. 1-B

Preoperative T2-weighted axial MRI at the C4-C5 disc space, depicting the measurements of the area for the cord (Fig. 1-A), the space available for the cord (Fig. 1-B), and rotation of the cord with respect to the vertebral body (Fig. 1-C). In Figure 1-A, the area within the yellow outline defines the perimeter of the spinal cord. In Figure 1-B, the yellow line indicates the anteroposterior canal space from the middle of the posterior vertebral body to the anterior aspect of the lamina in the center of the spinous process. 
The Journal of Bone \& Joint Surgery $\cdot$ JBjS. org Volume 94-A · Number $17 \cdot$ September 5, 2012
The Association Between Preoperative Spinal Cord

Rotation and Postoperative C5 Nerve Palsy
TABLE I Relationship Between C5 Palsy and Cord Rotation*

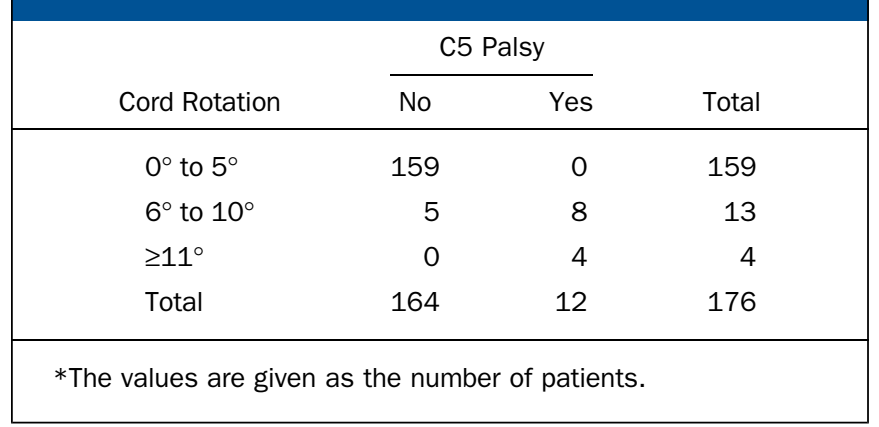

Massachusetts). These images were made with a fast-spin-echo sequence with an echo train length of 18, bandwidth of $31.25 \mathrm{~Hz}$, TR of $3400 \mathrm{~ms}, 47 \mathrm{TE}$ of $102 \mathrm{~ms}$, FOV of $18 \mathrm{~mm}$, matrix of $256 \times 256$, NSA of 3 NEX, slice thickness of $3 \mathrm{~mm}$, slice gap of $0.5 \mathrm{~mm}$, and scan acquisition time of two minutes and forty seconds.

\section{Source of Funding}

There was no funding source for this investigation.

\section{Results}

The mean age (and standard deviation) of the 176 patients was $49.76 \pm 11.47$ years (range, twenty-two to seventyeight years). The average body mass index (BMI) was $28.62 \pm$ 5.51. Sixty-six of the 176 patients smoked, fourteen were diabetic, and ninety-eight were employed. The mean preoperative values for the NDI, SF-36 physical component summary score (PCS), and SF-36 mental component summary score (MCS) were 49 (range, 17 to 83), 30 (range, 13 to 62), and 43 (range, 9 to 64 ), respectively. The mean duration of symptoms prior to surgery was eighteen months. Axial neck pain was present in 144 of the 176 patients, and radiculopathy was present in 125 of the 176 patients. Bilateral radiculopathy was present in thirtyseven of the 176 patients, and sixty-seven of the 176 patients were myelopathic. The prevalence of postoperative C5 nerve palsy was $6.8 \%$ (twelve of 176). C5 palsy was recognized at a mean of 1.7 days (range, zero to ten days) postoperatively. Specifically, four patients had C5 nerve palsy on Postoperative Day 0; four, on Postoperative Day 1; one, on Postoperative Day 2; one, on Postoperative Day 3; one, on Postoperative Day 4; and one, on Postoperative Day 10. The mean values for the cross-sectional area for the cord, the space available for the cord, and the rotation of the cord were $1.5 \pm 0.4 \mathrm{~cm}^{2}, 9.6 \pm 1.8 \mathrm{~mm}$, and $2.8^{\circ} \pm 3.0^{\circ}$, respectively.
All patients with C5 nerve palsy had at least $6^{\circ}$ of cord rotation. Ninety-seven percent of patients without palsy had $<6^{\circ}$ of cord rotation, and only $3 \%$ of patients without palsy had $\geq 6^{\circ}$ of cord rotation (Table I). For our analysis, we classified patients into three types, with Type 1 indicating mild rotation $\left(0^{\circ}\right.$ to $\left.5^{\circ}\right)$, Type 2 indicating moderate rotation $\left(6^{\circ}\right.$ to $\left.10^{\circ}\right)$, and Type 3 indicating severe rotation $\left(\geq 11^{\circ}\right)$. C5 nerve palsy developed in zero of 159 patients in the Type- 1 group, eight of thirteen patients in the Type-2 group, and four of four patients in the Type- 3 group. A significant association was detected between the severity of cord rotation $\left(0^{\circ}\right.$ to $5^{\circ}$ versus $6^{\circ}$ to $10^{\circ}$ versus $\geq 11^{\circ}$ ) and palsy (point-biserial correlation $=0.94 ; \mathrm{p}<$ 0.001 ). To confirm that cord rotation was an independent predictor of postoperative C5 nerve palsy, a logistic regression with all of our predictors (age, sex, body mass index, employment status, tobacco use, diabetes mellitus, NDI, SF-36 PCS, SF-36 MCS, duration of symptoms, cross-sectional area for the cord, space available for the cord, and rotation of the cord) was done. That initial model was not estimable because of complete separation of the data points, meaning that the model predicted the outcome too successfully for maximum likelihood procedures. In other words, the maximum likelihood solution did not exist when all of these predictors were considered. The model was then used with all of the predictors except the rotation variable. In that model, none of the variables significantly predicted C5 palsy ( $p>0.05$ for all). Finally, logistic regression with just the rotation variable as a predictor significantly predicted palsy (odds ratio $=9.58 ; \mathrm{p}<0.05)$, confirming that rotation of the cord was an independent predictor of C5 palsy above and beyond the other variables.

The patients who developed a C5 palsy had a mean rotation of the cord of $10.3^{\circ} \pm 3.5^{\circ}$, whereas the patients without C5 palsy had a mean rotation of the cord of $2.1^{\circ} \pm 1.5^{\circ}$ (Fig. 2). We determined the diagnostic efficiency of the cutoffs of $6^{\circ}$ and $11^{\circ}$ of rotation (Table II). For $6^{\circ}$, the sensitivity was 1.00 , the specificity was 0.97 , the positive predictive value was 0.71 , and the negative predictive value was 1.00 ; the $95 \%$ confidence intervals are given in Table II. For $11^{\circ}$, the sensitivity was 0.33 , the specificity was 1.00 , the positive predictive value was 1.00 , and the negative predictive value was 0.95 (Table II). A cutoff value of $6^{\circ}$ identified all patients who developed C5 palsy but also was associated with a number of false-positive results. Meanwhile, a cutoff value of $11^{\circ}$ identified only those who developed C5 palsy but was associated with a number of falsenegative results.

TABLE II Diagnostic Efficiency of the Chosen Cutoffs *

\begin{tabular}{|ccccc|}
\hline Cord Rotation & Sensitivity & Specificity & $\begin{array}{c}\text { Positive Predictive } \\
\text { Value }\end{array}$ & $\begin{array}{c}\text { Negative Predictive } \\
\text { Value }\end{array}$ \\
\hline$\geq 6^{\circ}$ & $1.00(0.70$ to 1.00$)$ & $0.97(0.93$ to 0.99$)$ & $0.71(0.44$ to 0.89$)$ & $1.00(0.97$ to 1.00$)$ \\
$\geq 11^{\circ}$ & $0.33(0.11$ to 0.65$)$ & $1.00(0.97$ to 1.00$)$ & $1.00(0.40$ to 1.00$)$ & $0.95(0.91$ to 0.98$)$ \\
\hline$*$ The $95 \%$ confidence intervals are shown in parentheses. & & \\
\hline
\end{tabular}




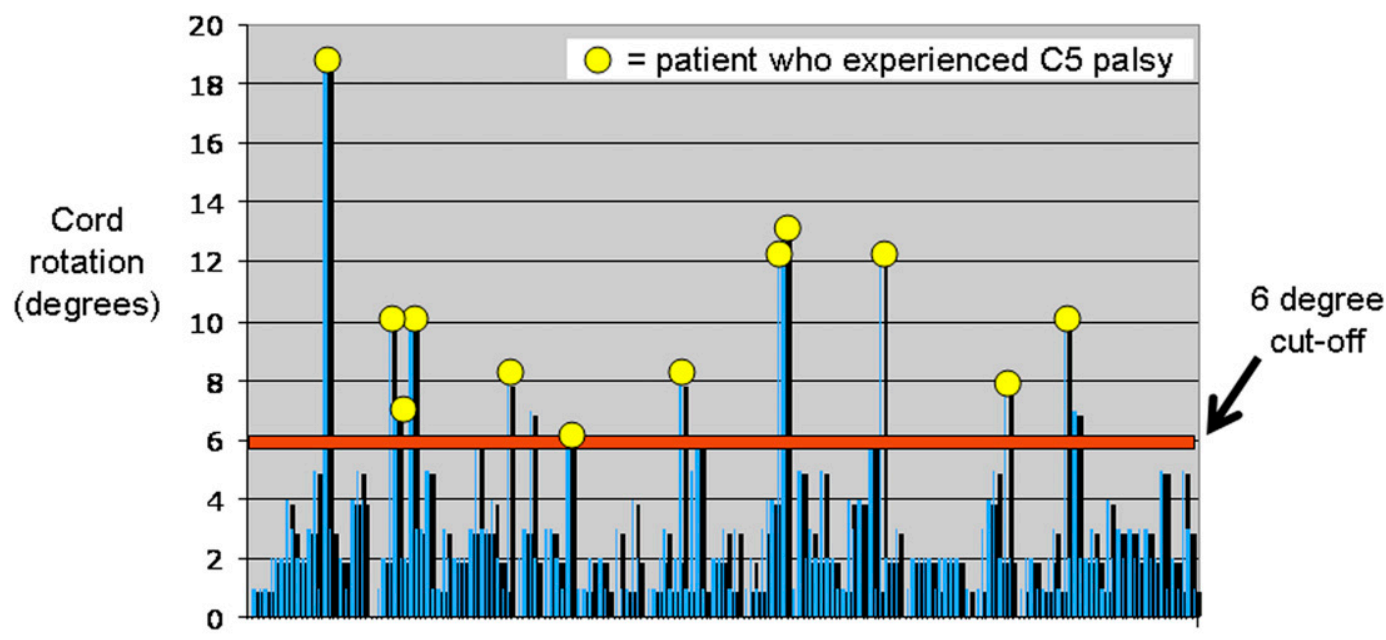

Fig. 2

\section{Patients}

Bar graph illustrating cord rotation for all patients. The red line indicates the $6^{\circ}$ cutoff, and the yellow circles indicate the patients who experienced a postoperative C5 palsy.

Regarding reliability, the average intraobserver difference for rotation of the cord in the group of twenty randomly chosen patients was $0.03^{\circ}$, whereas the average interobserver difference was $0.04^{\circ}$. The standard deviation of the difference between the average first measurements and second measurements by Observer 1 was $0.09^{\circ}$, with a repeatability coefficient of 0.19 and an interobserver coefficient of variation of $9.12 \%$. (A repeatability coefficient is an indicator of precision and represents the boundary with which the difference between two repeated test results may be expected to lie below, given a certain confidence.) Overall, there was no significant difference in the repeated measurements of Observer $1(p=0.98)$. The standard deviation of the difference between the average measurements of Observer 1 and Observer 2 was $0.08^{\circ}$, with a coefficient of variation of $9.04 \%$. Overall, there was no significant difference in the interobserver measurements $(\mathrm{p}=0.97)$.

\section{Discussion}

A nterior cervical decompression and arthrodesis is a proA cedure that allows the surgeon to decompress the cervical spine in a region of stenosis. It has been associated with good results when used for the treatment of compressive cervical myelopathy ${ }^{4}$. One complication that can adversely affect the outcome is the development of C5 nerve palsy. The purpose of the present study was to identify preoperative predictors of the development of postoperative C5 nerve palsy (specifically, rotation of the spinal cord). We grouped patients into three types, with Type 1 representing mild rotation $\left(0^{\circ}\right.$ to $\left.5^{\circ}\right)$, Type 2 representing moderate rotation $\left(6^{\circ}\right.$ to $\left.10^{\circ}\right)$, and Type 3 representing severe rotation $\left(\geq 11^{\circ}\right)$. The rates of C5 palsy for these groups were 0 of 159 , eight of thirteen, and four of four, respectively. These results indicate that patients with greater degrees of spinal cord rotation and subsequent cord displacement were at greater risk of postoperative C5 nerve palsy.
We chose rotation of the cord as an important measurement to consider for two reasons. The first reason was that a previous study identified rotation as a marker for nerve tension as the major component in the development of $\mathrm{C} 5$ palsies $^{17}$. The second reason was its ease of use and its reproducibility. The study by Imagama et al. ${ }^{6}$ demonstrated that foraminal stenosis was a measurement with low interobserver and intraobserver reliability. We chose not to examine foraminal stenosis because it cannot be used to identify the "at risk" population. Imagama et al. ${ }^{6}$, however, did identify superior articular process hypertrophy as an important factor for the development of C5 palsies. We believed that measuring this hypertrophy was cumbersome and less practical in a clinical setting, it but appears to have the advantage of being reproducible, unlike quantifying stenosis through the neural foramen ${ }^{6}$.

Preoperative rotation of the spinal cord appears to be an indicator of an increased risk of developing a C5 nerve palsy in association with anterior cervical spine surgery. Two valuable thresholds were identified in our analysis. A cutoff of $6^{\circ}$ identified all patients who developed C5 palsy but also was associated with a number of false-positive results. Meanwhile, a cutoff of $11^{\circ}$ identified only patients who developed C5 palsy but was associated with a number of false-negative results.

These findings should be interpreted with some caution. They are based on retrospective data and are exploratory in nature. Replication of these findings in prospective studies is important. As part of these future studies, the diagnostic efficiency of the present cutoffs should be measured again to confirm their accuracy, usability, and generalizability. Nonetheless, these findings are potentially important as they provide preliminary evidence that preoperative cord rotation may be a strong and significant predictor of C5 nerve palsy postoperatively. If future studies confirm this finding prospectively, modification of surgical procedures may be warranted. 
The Journal of Bone \& Joint Surgery JbjS. org Volume 94-A · Number $17 \cdot$ September 5, 2012
The Association Between Preoperative Spinal Cord

Rotation and Postoperative C5 Nerve Palsy
Mark S. Eskander, MD

Department of Orthopaedic Surgery, University of Pittsburgh Medical Center, 3471 Fifth Avenue, Pittsburgh, PA 15213. E-mail address: eskanderms@upmc.edu

Steve M. Balsis, PhD

Department of Psychology,

Office 286 Psychology Building,

Texas A\&M University, College Station, TX 77843

Chris Balinger, MD

Michelle E. Aubin, MD

Jeffrey Lange, MD

Jason Eck, DO, MS
Patrick J. Connolly, MD

Department of Orthopedic Surgery,

University of Massachusetts Medical School, 55 Lake Avenue, Worcester, MA 01655

Caitlin M. Howard, MD

Nicholas W. Lewing, MD

Jonathan P. Eskander, MD

Tulane University Medical School,

1430 Tulane Avenue, New Orleans, LA 70112

Louis G. Jenis, MD

The Boston Spine Group,

299 Washington Street,

Newton, MA 02458

\section{References}

1. Uematsu Y, Tokuhashi $Y$, Matsuzaki H. Radiculopathy after laminoplasty of the cervical spine. Spine (Phila Pa 1976). 1998 Oct 1;23(19):2057-62.

2. Fan D, Schwartz DM, Vaccaro AR, Hilibrand AS, Albert TJ. Intraoperative neurophysiologic detection of iatrogenic $C 5$ nerve root injury during laminectomy for cervical compression myelopathy. Spine (Phila Pa 1976). 2002 Nov 15;27(22):2499-502.

3. Hasegawa K, Homma T, Chiba Y. Upper extremity palsy following cervical decompression surgery results from a transient spinal cord lesion. Spine (Phila Pa 1976). 2007 Mar 15;32(6):E197-202.

4. Busch G. Anterior fusion for cervical spondylosis. J Neurol. 1978 Oct 25; 219(2):117-26.

5. Rogers LC. Some surgical problems of the cervical spine. Proc R Soc Med. 1961 Jan;54:49-52.

6. Imagama S, Matsuyama Y, Yukawa Y, Kawakami N, Kamiya M, Kanemura T, Ishiguro N; Nagoya Spine Group. C5 palsy after cervical laminoplasty: a multicentre study. J Bone Joint Surg Br. 2010 Mar;92(3):393-400.

7. Scoville WB. Cervical spondylosis treated by bilateral facetectomy and laminectomy. J Neurosurg. 1961 Jul;18:423-8.

8. Stoops WL, King RB. Neural complications of cervical spondylosis: their response to laminectomy and foramenotomy. J Neurosurg. 1962 Nov;19:986-99.

9. Nassr AN, Eck JC, Ponnappan RK, Zanoun RR, Donaldson WF III, Kang J. The incidence of C5 palsy after multilevel cervical decompression procedures: a review of 750 consecutive cases. Poster presented at the Annual Meeting of the American Academy of Orthopaedic Surgeons; 2009 Feb 25-28; Las Vegas, NV. Poster no. P378.

10. Sakaura H, Hosono N, Mukai Y, Ishii T, Yoshikawa H. C5 palsy after decom pression surgery for cervical myelopathy: review of the literature. Spine (Phila Pa 1976). 2003 Nov 1;28(21):2447-51.
11. Tsuzuki N, Abe R, Saiki K, Zhongshi L. Extradural tethering effect as one mechanism of radiculopathy complicating posterior decompression of the cervical spinal cord. Spine (Phila Pa 1976). 1996 Jan 15;21(2):203-11.

12. Shiozaki T, Otsuka H, Nakata $Y$, Yokoyama $T$, Takeuchi $K$, Ono A, Numasawa $T$, Wada K, Toh S. Spinal cord shift on magnetic resonance imaging at 24 hours after cervical laminoplasty. Spine (Phila Pa 1976). 2009 Feb 1;34(3):274-9.

13. Chiba K, Toyama $Y$, Matsumoto $M$, Maruiwa $H$, Watanabe $M$, Hirabayashi $K$. Segmental motor paralysis after expansive open-door laminoplasty. Spine (Phila Pa 1976). 2002 Oct 1;27(19):2108-15.

14. Hosono N, Miwa T, Mukai Y, Takenaka S, Makino T, Fuji T. Potential risk of thermal damage to cervical nerve roots by a high-speed drill. J Bone Joint Surg Br. 2009 Nov;91(11):1541-4.

15. Park $P$, Lewandrowski KU, Ramnath $S$, Benzel EC. Brachial neuritis: an underrecognized cause of upper extremity paresis after cervical decompression surgery. Spine (Phila Pa 1976). 2007 Oct 15;32(22):E640-4.

16. Tsuzuki N, Abe R, Saiki K, Okai K. Paralysis of the arm after posterior decompression of the cervical spinal cord. II. Analyses of clinical findings. Eur Spine J. 1993 Dec;2(4):197-202.

17. Shuichi K, Masatoshi S, Koichi K, Aritetsu K, Masato T, Tetsuya N. Prospective comparative study of the incidence of postoperative segmental motor paralysis between open-door and double-door laminoplasty. Read at the CSRS 36th Annua Meeting; 2008 Dec 4-6;Austin, TX. Paper no. 7.

18. Vernon $\mathrm{H}$, Mior S. The Neck Disability Index: a study of reliability and validity. J Manipulative Physiol Ther. 1991 Sep;14(7):409-15.

19. Ware JE, Gandek B, the IQOLA Project Group. The SF-36® Health Survey: de velopment and use in mental health research and the IQOLA Project. Int J Mental Health. 1994;23(2):49-73. 